\title{
LAPAROSCOPIC VASECTOMY IN AFRICAN SAVANNAH ELEPHANT (LOXODONTA AFRICANA); SURGICAL TECHNIQUE AND RESULTS
}

\author{
Hendrik J. Marais, B.V.Sc., M.Sc., Dean A. Hendrickson, D.V.M, Dipl. A.C.V.S., Mark Stetter, \\ D.V.M. Dipl. A.C.Z.M., Jeffery R. Zuba, D.V.M., Mark Penning B.V.Sc., Jess Siegal-Willott, D.V.M., \\ and Christine Hardy, D.V.M.
}

\begin{abstract}
Several small, enclosed reserves in southern Africa are experiencing significant elephant population growth, which has resulted in associated environmental damage and changes in biodiversity. Although several techniques exist to control elephant populations, e.g., culling, relocation, and immunocontraception, the technique of laparoscopic vasectomy of free-ranging bull elephants was investigated. Bilateral vasectomies were performed in 45 elephants. Of these elephants, one died within $24 \mathrm{hr}$ of recovery and two had complications during surgery but recovered uneventfully. Histologic examination confirmed the resected tissue as ductus deferens in all the bulls. Most animals recovered uneventfully and showed no abnormal behavior after surgery. Complications recorded included incisional dehiscence, 1 full-thickness and 2 partial-thickness lacerations of the large intestine, and initial sling-associated complications, for example, deep radial nerve paresis. One bull was found dead 6 weeks after surgery without showing any prior abnormal signs. Vasectomy in free-ranging African bull elephants may be effectively performed in their normal environment. The surgical procedure can be used as a realistic population management tool in free-ranging elephants without major anesthetic, surgical, or postoperative complications.

Key words: African savannah elephant, laparoscopy, Loxodonta africana, surgical technique, vasectomy.
\end{abstract}

\section{BRIEF COMMUNICATION}

The project was performed with the permission of the animal use and care committees of the University of Pretoria and the San Diego Zoo Global. The surgeries were performed under field conditions in 7 nature reserves in southern Africa. Forty-five bull African elephants, which ranged between 7 and 40 years, were anesthetized and had a laparoscopic vasectomy performed while the elephant was in a standing-like position. Initially, the animals were positioned in a sling with the limbs being splinted for extra support, but, with later procedures, all the animals were positioned in a sling but without the leg braces. While anesthesia was maintained by using a

From the Department of Companion Animal Clinical Studies, Private Bag X04, Faculty of Veterinary Science, Onderstepoort, 0110, University of Pretoria, South Africa (Marais); the College of Veterinary Medicine and Biomedical Sciences, Colorado State University, 1620 Campus Delivery, Fort Collins, Colorado 80523, USA (Hendrickson, Stetter, Hardy); the San Diego Zoo Safari Park, Escondido, California, 92027, USA (Zuba); Disney's Animals, Science and Environment, Walt Disney Parks and Resorts, P.O. Box 10000, Lake Buena Vista, Florida 32830, USA (Penning); the Smithsonian Institution's National Zoological Park, 3001 Connecticut Avenue, Washington, D.C. 37012, USA (Siegal-Willot). Correspondence should be directed to Dr. Marais (johan.marais@up.ac.za). continuous infusion of etorphine $(9.8 \mathrm{mg} / \mathrm{ml}$; Captivon, Wildlife Pharmaceuticals SA, Karino, South Africa) mixed in a 1-L bag of $0.9 \%$ saline solution and administered at $2.5 \mathrm{mg} / \mathrm{hr}$ i.v., the bulls were ventilated with oxygen via a cuffed endotracheal tube and positive pressure ventilation (anesthetic protocols and data to be published elsewhere). ${ }^{9}$ After achieving the proper depth of anesthesia, the i.v. drip was titrated to effect. An $8-10-\mathrm{cm}$ skin incision was made by extending ventrally from a point located roughly midway between the last rib and the tuber coxae and extended through the subcutaneous tissue, external oblique, internal oblique, and transversus abdominal muscles. The fibroelastic layer of the peritoneum was grasped with Vulsellum forceps, and Mayo scissors were used to sharply remove fat and portions of this layer until the peritoneum was identified. A specially designed cannula and laparoscope $(25-\mathrm{mm}$ diameter and $980-\mathrm{mm}$ length) with a $10-\mathrm{mm}$, centrally located working channel (Karl Storz GmbH and Co, Tuttlingen, 78501, Germany) was introduced into the peritoneal cavity through an incision in the peritoneum, which was subsequently closed with a purse-string suture by using 0 polyglyconate suture material (Maxon, Covidien, Mansfield, Ohio, 02048, USA). The abdominal cavity was initially insufflated to a pressure of $0.5-1$ psi (26$51.7 \mathrm{~mm} \mathrm{Hg}$ ) with filtered ambient air. If any of the abdominal organs obstructed the field of view 
and made it difficult to visualize the testis and ductus deferens, then the intra-abdominal pressure was increased to 3 psi $(155.1 \mathrm{~mm} \mathrm{Hg})$ for a short period of time. For triangulation, a $2-\mathrm{cm}$ incision was made through the skin at the same level and $8-10 \mathrm{~cm}$ cranial to the primary laparoscopic portal to create the second laparoscopic portal. An 11-mm-diameter cannula with a sharp conical obturator was introduced, and once the peritoneum was tented, the obturator was removed and replaced with a 10 -mm-diameter, 75140-cm laparoscopic scissors (Surgical Direct, Deland, Florida 32720, USA). The peritoneum then was incised, and the scissors were directed toward the testis. The ductus deferens was identified and secured with traumatic grasping forceps through the laparoscope channel, and a 40- to $80-\mathrm{mm}$ segment was sharply removed, without any ligation. The peritoneum and body wall were closed, and the procedure was repeated on the contralateral side. Removal of the resected tissue was performed through the primary laparoscopic cannula. In an effort to decrease total surgical time, the incision and the entrance into the abdominal cavity on the contralateral side was performed at the same time while closure was being completed on the first side. Anesthesia was reversed with naltrexone $(50 \mathrm{mg} /$ animal i.v.; Trexonil, Wildlife Pharmaceuticals SA, Karino, South Africa) and diprenorphine (36-42 mg/ animal i.v.; Diprenorphine, Wildlife Pharmaceuticals SA, Karino, South Africa), and all the animals were standing within $3 \mathrm{~min}$. After the surgery, the animals were monitored on a daily basis to record behavior and incision healing for 4 wk and then weekly until 6 mo after surgery.

Bilateral vasectomies (surgery time, 45-210 min) were successful in all the elephant bulls. In 1 elephant, the large intestinal lumen was invaded and the bowel tear was sutured extracorporeally. In 2 animals, superficial lacerations were caused on the large intestinal seromuscular layer. All the animals recovered uneventfully and showed no abnormal behavior during the following weeks. One elephant was found dead 6 wk after surgery without having shown abnormal signs or behavior. Younger bulls had relatively little fat around the ductus deferens, whereas older bulls had a fair amount of fat in the area, which made visualization of the ductus deferens sometimes difficult. This problem can be overcome by performing the vasectomy during the month or months after musth, during which the bull would have lost much weight. ${ }^{2}$ Complications recorded include incisional dehiscence, sling-associated complica- tions such as deep radial nerve paresis in 3 elephants, and 1 death probably due to a combination of the sling, length of surgery, and difficulty in recovery. Histologic examination confirmed the resected tissue as ductus deferens in all animals.

Sterilization of male elephants by using laparoscopic vasectomy is a viable option for population control and is effective at the population level for several reasons. Bulls only need to be sterilized once, whereas females have to be treated several times with either gonadotropin-releasing hormone $(\mathrm{GnRH})$ or porcine zona pellucida immunocontraception, or GnRH-agonist implants. ${ }^{3,4}$ Treatment of older solitary males can be done far from any herd, whereas immunocontraception of females is usually done from a helicopter. Although results of a study has shown that immunocontraception has a minimal influence on elephant social behavior in the intermediate period, ${ }^{1}$ another study performed on horses describes that this procedure has significant consequences for social behavior and that porcine zona pellucida application may disrupt social ties among individuals and inhibit normal social functioning at the population level. ${ }^{6}$ However, Druce et al. ${ }^{4}$ reported that, although some avoidance behavior was observed in their study elephant population, no significant change in mobility within family groups before, during, and after the annual darting procedure was seen. These researchers, however, do mention that longer-term monitoring studies would be essential to determine whether immunocontraception may have long-term behavioral consequences. In addition, by using immunocontraception in females, booster vaccinations need to be administered to the correct females each time. Although immunocontraception has been proven to be effective and safe, the technique requires multiple manipulations and repeated treatments.

Male elephants come into musth at approximately 30 to $35 \mathrm{yr}$ of age and reach their reproductive peak at $40 \mathrm{yr}$ of age. ${ }^{7}$ These bulls may be successfully treated by laparoscopic vasectomy to prevent them from siring calves. Younger bulls also may be vasectomized at an earlier age to prevent them from siring calves once they reach maturity and start coming into musth. When depending on the reserve's requirements and to minimize potential physical, social and ecological adverse effects, such as the prolonged absence of newborn calves and the continued cycling of females, a predetermined number of select bulls may be left to institute breeding. ${ }^{5}$ 
The ends of the ductus deferens were not ligated. Spermatozoa are haploid cells that are generally immunogenic, and, therefore, the formation of sperm granuloma in the peritoneal cavity may be a possibility. However, the vasectomy procedure in all of these bulls was performed when they were not in musth, and, therefore, the possibility of them being sexually active at that time was minimal. Trauma from the laparoscopic scissors to the end of the ductus deferens would probably lead to fibrosis and closure of this structure in a relative short time period. In a study that involved 2 prospective vasectomy series, a sperm granuloma was intentionally allowed to form by not sealing the testicular end of the vas. The sperm granuloma resulted in no instance of orchialgia, and the only complication recorded was a greater risk of spontaneous recanalization. ${ }^{8}$ This latter problem could only be solved by more careful sealing of the upper end of the vas. In this current study, recanalization was highly unlikely because 4 to $8 \mathrm{~cm}$ of the ductus deferens was removed.

Laparoscopic vasectomy can be effectively performed on the African elephant in its natural environment. Special attention is required to minimize the risk of intestinal laceration during the approach, especially because it is not possible to fast the elephant before surgery. Long-term monitoring studies would be essential to better understand the adaptive management and control of elephants and whether vasectomy may have long-term behavioral consequences.

Acknowledgments: The authors would like to recognize and thank several key individuals who have been critical in the success of this work: Douw Grobler, Li-Ann Small, J. J. Van Altena, Adrien Tordiffe, Deena Brenner, Frik Stegmann, Luis Rubio-Martinez, and Audrey Delsink. The authors would also like to recognize the following wildlife reserves for their support and collaboration: Phinda, Makalali, Welgevonden, Songimvelo, Pongola, Selati, and Hlane.

\section{LITERATURE CITED}

1. Bertschinger H. J., A. K. Delsink, J. F. Kirkpatrick, D. Grobler, and J. J. van Altena. 2005. The use of pZP and GnRH vaccines for contraception and control of behaviour in African elephants. In: Rutberg A.T. (ed.). The Role of Immunocontraception. Humane Society Press, Washington, D.C. Pp. 13-18.

2. Bokhout, B., M. Nabuurs, and M. de Jong. 2005. Vasectomy of older bulls to manage elephant overpopulation in Africa: a proposal. Pachyderm. 39: 97-103.

3. Delsink, A. K., J. J. van Altena, D. Grobler, H. J. Bertschinger, J. F. Kirkpatrick, and R. Slotow. 2007. Implementing immunocontraception in free-ranging African elephants at Makalali Conservancy. Journal of South African Veterinary Association. 78: 25-30.

4. Druce, H. C., R. L. Mackey, K. Pretorius, and R. Slotow. 2013. In press. The intermediate term effects of PZP immunocontraception: behavioural monitoring of the treated elephant females and associated family groups. PLoS ONE 6(12):e27952. doi:10.1371/ Journal.pone.0027952.

5. Kerley, G. I. H., and A. M. Shrader. 2007. Elephant contraception: silver bullet or potentially bitter pill? South African Journal of Science. 103: 181-182.

6. Nunez, C. M. V., J. S. Adelman, C. Mason, and D. I. Rubenstein. 2009. Oestrus behaviour and female choice in the African elephant. Applied Animal Behaviour Science. 117: 74-83.

7. Poole, J. H., P. C. Lee, N. Njiraini, and C. J. Moss. 2011. In: Moss, C., H. Croze, and P. C. Lee (eds.). The Amboseli Elephants-A Long-term Perspective on a Long-lived Mammal. University of Chicago Press, Chicago, Illinois. Pp. 275-284.

8. Shapiro, E. L., and S. J. Silber. 1979. Open-ended vasectomy, sperm granuloma and postvasectomy orchialgia. Fertility and Sterility. 32: 546-550.

9. Stetter, M., and D. Hendrickson. 2012. Laparoscopic surgery in the elephant and rhinoceros. In: Fowler, M. E., and R. E. Miller (eds.). Zoo and Wild Animal Medicine, vol. 7. Elsevier Saunders, St. Louis, Missouri. Pp. 524-530.

Received for publication 16 August 2012 